\title{
Theoretical investigation on structural evolution, energetic stability trend and electronic properties of $\mathrm{Au}_{n} \mathrm{Cd}(n=1-12)$
}

\author{
JIAN SUI ${ }^{\mathrm{a}, \mathrm{b}, *}$, XINQIANG WANG ${ }^{\mathrm{a}}$ and PANLONG AN ${ }^{\mathrm{b}}$ \\ ${ }^{a}$ College of Physics, Chongqing University, Chongqing 400044, People's Republic of China

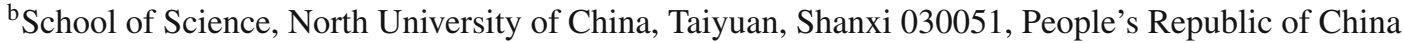 \\ e-mail: future_jan@163.com; xqwang@cqu.edu.cn
}

MS received 9 December 2013; revised 17 March 2014; accepted 20 March 2014

\begin{abstract}
We systematically studied the geometrical structures, relative stabilities, electronic properties and chemical hardness of $\mathrm{Au}_{n} \mathrm{Cd}(n=1-12)$ clusters based on the framework of the density functional theory using relativistic all-electron methods. Low-lying energy structures include two-dimensional and three-dimensional geometries. Especially, all the lowest-energy structures of $\mathrm{Au}_{n} \mathrm{Cd}(n=1-12)$ clusters are inclined to be planar geometries with slight distortion, in which the dopant $\mathrm{Cd}$ atom has higher coordination at $n=2-6$, but lower coordination at $n=7-12$. The fragmentation energies, second-order difference of energies, the highest occupied-lowest unoccupied molecular orbital gaps and chemical hardness of $\mathrm{Au}_{n} \mathrm{Cd}$ and $\mathrm{Au}_{n+1}$ exhibit a pronounced even-odd alternations phenomenon in the reverse order This result indicates that the geometrical, electronic and chemical stabilities of $\mathrm{Au}_{n} \mathrm{Cd}$ with even number of valence electrons are higher than those of the neighbouring $\mathrm{Au}_{n} \mathrm{Cd}$ with odd number of valence electrons and corresponding $\mathrm{Au}_{n+1}$ with odd number of valence electrons. Additionally, $4 d$ valence electrons orbital of impurity $\mathrm{Cd}$ atom in $\mathrm{Au}_{n} \mathrm{Cd}$ hardly joins in the orbital interactions compared with $5 d$ valence electrons of corresponding $\mathrm{Au}$ atom in $\mathrm{Au}_{n+1}$. $\mathrm{Au}-\mathrm{Cd}$ bonds of $\mathrm{Au}_{n} \mathrm{Cd}$ clusters are weaker and have more obviously ionic-like characteristics than the corresponding $\mathrm{Au}-\mathrm{Au}$ bonds of $\mathrm{Au}_{n+1}$.
\end{abstract}

Keywords. $\quad \mathrm{Au}_{n} \mathrm{Cd}$ cluster; stability pattern; electronic property; population analysis; ionic-like characteristic

\section{Introduction}

Heteroatomic nanoclusters have received much attention due to their distinctive catalytic, structural, electronic, magnetic and optical properties. ${ }^{1-3}$ There is a growing interest in transition metal-doped gold clusters because transition metal elements can strongly influence the chemical and physical properties of host gold clusters. ${ }^{4-8}$ For instance, Bonačić-Koutecký et $a l .{ }^{9}$ studied the structure and electronic properties of bimetallic $\operatorname{Ag}_{m} \mathrm{Au}_{n}(3<(m+n)<5)$ clusters, and found that the charge transfer from Ag to Au plays a dominant role in the structure of the bimetallic clusters. The ground geometric structures, the stability and electronic properties of the small $\mathrm{Au}_{n} \mathrm{M}(n=1-7$, $\mathrm{M}=\mathrm{Ni}, \mathrm{Pd}, \mathrm{Pt}$ ) clusters were researched, ${ }^{10}$ and it was found that the stability of Pd- and Pt-doped gold clusters is evidently changed due to the relative strong bonding interaction contributed by $d$-electrons, and the $d-d$ and $s-d$ interactions between impurities and gold atoms can markedly modify the electronic properties of doped

\footnotetext{
*For correspondence
}

gold clusters. The theoretical study ${ }^{11}$ of $\mathrm{Au}_{n} M^{+}$clusters $(M=\mathrm{Sc}, \mathrm{Ti}, \mathrm{V}, \mathrm{Cr}, \mathrm{Mn}, \mathrm{Fe}, \mathrm{Au} ; n \leq 9)$ discovered that the positive charge of the cationic $\mathrm{Au}_{n} M^{+}$clusters, which is localized mainly in the impurity, and the magnetic and geometrical configurations are strongly correlated with cluster sizes. The geometric and electronic properties of neutral and anionic bimetallic vanadium-gold clusters $\mathrm{Au}_{n} \mathrm{~V}(n=1-14)$ were theoretically studied, ${ }^{6}$ which found that the smaller ground-state clusters of $\mathrm{Au}_{\mathrm{n}} \mathrm{V}$ prefer 2D geometries up to $\mathrm{Au}_{8} \mathrm{~V}$ involving a weak charge transfer, but the larger systems bear 3D conformations with a more effective electron transfer from Au to V. Neukermans et al. ${ }^{12}$ studied elementdependent $3 d$ electron delocalization of $3 d$-shell atoms (Sc, Ti, V, Cr, Mn, Fe, Co, Ni), which revealed that the lightest $3 d$ elements $(\mathrm{Sc}, \mathrm{Ti})$ delocalize their $4 s$ and $3 d$ electrons, while for the heavier $3 d$ elements (Cr, Mn, Fe, $\mathrm{Co}, \mathrm{Ni}$ ), only $4 s$ electrons are delocalized. Moreover, a number of researches about the adsorption of doped Au clusters were reported, ${ }^{13-16}$ showing the difference of catalysis from the adsorption of pure gold clusters. These examples sufficiently illustrate that the doping metal atom of gold-based mixed cluster has a notable act to change the geometries, chemical 
activities and stabilities of the corresponding gold cluster. Hence, the transition metal-doped gold clusters are expected to design the desired structural, magnetic, and chemical properties for potential applications. ${ }^{17-19}$

The transition metal $\mathrm{Cd}$ has extensive applications in electronics, batteries and nuclear technologies and special alloys. An experiment ${ }^{20}$ discovered that the $\mathrm{Cd}_{3}$ and $\mathrm{Cd}_{5}$ clusters can be constructed as metal-organic frameworks with small multidentate ligands. Another investigation $^{21}$ showed that the cadmium perchlorate hydrate is simple, novel and highly efficient catalyst, which synthesizes $\alpha$-aminophosphonates with excellent yields under mild and solvent-free conditions. In addition, Frischmann et al. ${ }^{22}$ found that the stable heptanuclear cadmium cluster complex can organize into tunable metallocavitand capsules with accessible metal sites on their interiors, and these capsule structures are alluring candidates for host-guest catalysis and molecular recognition. Furthermore, nano-sized cadmium compounds have many novel uses. In the experiment, ${ }^{23}$ the CdSe nanoparticle is found to behave as a semiconductor material. The development ${ }^{24}$ of cadmiumcontaining nanoparticles, known as quantum dots, show great promise for treatment and diagnosis of cancer and targeted drug delivery, owing to their size-tunable fluorescence and ease of functionalization for tissue targeting. Especially for $\mathrm{Cd}-\mathrm{Au}$ system, 'the Shape Memory Effect' (SME) in gold cadmium (AuCd) alloy was discovered early in 1932, which is the first record of the shape memory transformation. Therefore, many chemists and physicists have drawn much attention to the properties of cadmium gold alloy. Particularly, a few studies demonstrated that nanometer-sized $\mathrm{Au}-\mathrm{Cd}$ particles exhibit even better properties at small scale than their bulk counterparts. Asaka et al. ${ }^{25}$ found that the $\beta_{2}$ phase in the $\mathrm{Au}-\mathrm{Cd}$ nanosized alloys becomes stable and the martensitic transformation temperatures are lowered with size decreasing, which is much different from the corresponding bulks. Later, it was also observed that the martensitic transformation start temperature, Ms, of nanometer-sized AuCd particles was determined to be about $49 \mathrm{~K}$ and thus drastically lesser than that of the AuCd bulk alloys. ${ }^{26}$ Although $\mathrm{Au}-\mathrm{Cd}$ nanosystems have wide applications, the systematical and substantial studies on Cd-doped $\mathrm{Au}$ nanosystem are still relatively rare. It is well known that $\mathrm{Au}-\mathrm{Cd}$ clusters of small size can establish a good bridge for the overall realization of a Cd-doped $\mathrm{Au}$ nanosystem.

On the other hand, cadmium and its congeners ( $\mathrm{Zn}$ and $\mathrm{Hg}$ ) are not always considered transition metals, in that they do not have partly filled $d$ or $f$ electron shells in the elemental or common oxidation states. ${ }^{27}$
However, gold atom has a completely filled $d$-shell and one valence s electron in the electronic ground state, and therefore Au clusters often are regarded as simple metal clusters similar to alkali metal clusters. Considering that cadmium, including its congeners ( $\mathrm{Zn}$ and $\mathrm{Hg}$ ), and gold atoms have distinctive valence electronic configurations compared to other transition metals, the impurity $\mathrm{Cd}$ atom including $\mathrm{Hg}$ and $\mathrm{Zn}$ inevitably influences the stability and electronic structure of bare gold clusters when doping $\mathrm{Cd}$ or its congener atom. Particularly, previous reportedly experimental and theoretical investigations of $\mathrm{Au}$ clusters doped with $\mathrm{Hg}$ and $\mathrm{Zn}$ have indicated that the electronic and geometric characteristics of $\mathrm{Hg}$ or $\mathrm{Zn}$-doped gold clusters are extraordinary and different from another transition metal-doped gold system. The photoelectron spectra of $\mathrm{Au}_{n} \mathrm{Zn}$ were studied experimentally through anion photoelectron spectroscopy, ${ }^{28}$ exhibiting even-odd alternation of electron affinities and characteristic spectral changes with cluster size. In the theoretical research ${ }^{29}$ on $\mathrm{Au}_{n} \mathrm{Zn}(n=1-6)$, it was revealed that all the lowestenergy isomers of $\mathrm{Au}_{n} \mathrm{Zn}$ clusters and their cations are 2D structures very similar to those of pure Au cluster. Likewise, $\mathrm{Au}_{n} \mathrm{Hg}$ cluster was investigated using the relativistic effective core potential model, ${ }^{30}$ also showing that equilibrium geometries prefer one- and two dimensional structures without nonplanar structures in the case of small cluster size. A study ${ }^{18}$ discovered that the $s-p$ orbital overlap of the HOMO of $\mathrm{Au}_{n} \mathrm{Zn}^{+}$, which is responsible for the bonding character between $\mathrm{Au}$ and $\mathrm{Zn}$ in the HOMO, has a stabilizing effect on the HOMO, and the energy lowering of the HOMO results in a large HOMO-LUMO energy gap of the $\mathrm{Au}_{n} \mathrm{Zn}^{+}$clusters. In a study ${ }^{31}$ on the $\mathrm{Au}_{n} \mathrm{Hg}_{m}$ system, it is found that all local minima and transition structures of $\mathrm{Au}_{n} \mathrm{Hg}_{m}$ clusters are planar. Meanwhile, this article also pointed out that $\mathrm{Au}_{2} \mathrm{Cd}$ structure prefers a linear conformation with terminal gold atoms. Furthermore, in these investigations, we found that when cluster size is smaller, the energy minima states of the $\mathrm{Au}_{n} \mathrm{Zn} / \mathrm{Hg}$ neutral or ionic clusters usually prefer two dimensional structures. Recently, a density functional comparison study ${ }^{32}$ was presented on $\mathrm{Au}_{32}$ cluster doped with group IIB atoms, showing that the HOMO-LUMO gap of the $\mathrm{Au}_{32}$ cage doped with $\mathrm{Zn}, \mathrm{Cd}$ or $\mathrm{Hg}$ atom all remain almost similar to that of the $\mathrm{Au}_{32}$ cage for high-symmetry clusters, and it decreases for the low-symmetry isomers. Here, considering that $\mathrm{Cd}, \mathrm{Hg}$ and $\mathrm{Zn}$ all possess same valence electronic configuration $s^{2} d^{10}$, interesting questions are presented: Likewise, for cadmium from the group IIB, will the lowest-energy states of $\mathrm{Au}_{n} \mathrm{Cd}$ still retain planar structures? How will the electronic and chemical properties of pure gold cluster be changed obviously after 
doping a cadmium atom and then will these properties of Cd-doped gold clusters be similar to those of $\mathrm{Zn}$ or Hg-doped gold systems?

In our study, we systematically investigate the influence of impurity $\mathrm{Cd}$ atom on the geometrical structures, relative stabilities, electronic properties, interaction between the dopant and host atoms and chemical hardness of $\mathrm{Au}_{n} \mathrm{Cd}(n=1-12)$ clusters, and the whole calculation is based on density functional theory with the generalized gradient approximation at BP level and all-electron scalar relativistic effects. In comparison with pure gold clusters, we hope to find the evolutionary patterns and characteristics with the growth of the cluster size. We expect our research to be constructive in understanding the influence of material structure on its properties and guide further theoretical and experimental studies

\section{Computational Details}

The geometrical structures and electronic properties of $\mathrm{Au}_{n} \mathrm{Cd}(n=1-12)$ clusters are calculated using the spin-polarized density functional theory (DFT) in the DMOL $^{3}$ program package. ${ }^{33-35}$ The generalized gradient approximation (GGA) in the Becke exchange plus Perdew correlation (BP) $)^{36,37}$ functional is chosen in the calculations. A double-numerical basis set including $d$-polarization functions (DNPs) are adopted for the description of the electronic wave functions. Due to heavy elements of gold and cadmium, ${ }^{33,38-46}$ the all-electron scalar relativistic (AER) method is used in our work for greater accuracy of calculations. Meanwhile, the convergence criteria are set with 0.002 $\mathrm{Ha} / \AA$ for the forces, $0.005 \AA$ for the displacement, and $10^{-5} \mathrm{Ha}$ for the energy change in our calculation. To ensure the reliability of initial structures, first, we re-optimized the structures of pure gold clusters in previous studies ${ }^{45,47-49}$ with the same methods and same parameters. And then, based on these optimized equilibrium geometries of pure gold clusters, we can construct numerous possible initial structures of $\mathrm{Au}_{n} \mathrm{Cd}$ clusters by a $\mathrm{Cd}$ atom replacing one gold atom at every possible nonequivalent site or by adding $\mathrm{Cd}$ atom directly on each possible non-equivalent site in the $\mathrm{Au}_{n+1}$ cluster. In the meantime, we also refer to the structures available of doped gold cluster in previous literatures. $^{9-11,29,49,50}$ These possible initial energy structures of $\mathrm{Au}_{n} \mathrm{Cd}$ include one, two and three-dimensional geometries. Moreover, all initial structures are optimized by relaxing the atomic positions fully without any symmetry constraints. Additionally, the harmonic vibrational frequencies of all configurations are computed in order to confirm all the optimized structures that correspond to the local energy minima.

To examine the reliability of our scheme, we calculate the bond-length, dissociation energy and vibrational frequency of $\mathrm{Au}_{2}, \mathrm{Cd}_{2}$ and $\mathrm{AuCd}$ dimers for comparison with the corresponding experimental and theoretical data. In our calculations, the bondlength, dissociation energy and vibrational frequency are $2.489 \AA, 2.296 \mathrm{eV}$ and $181.5 \mathrm{~cm}^{-1}$ for $\mathrm{Au}_{2}$ dimer and $3.59 \AA, 0.0306 \mathrm{eV}$ and $30.7 \mathrm{~cm}^{-1}$ for $\mathrm{Cd}_{2}$ dimer, respectively. These calculated values are in good accordance with the corresponding experimental results ${ }^{51-56}$ of $2.47 \AA, 2.29 \mathrm{eV}$ and $190.9 \mathrm{~cm}^{-1}$ for $\mathrm{Au}_{2}$ and $4.07 \AA$, $0.0378 \mathrm{eV}$ and $23.0 \mathrm{~cm}^{-1}$ for $\mathrm{Cd}_{2}$, respectively. Additionally, for $\mathrm{AuCd}$ dimer, the dissociation energy of $1.02 \mathrm{eV}$, bond-length of $2.630 \AA$ and frequency of $151 \mathrm{~cm}^{-1}$ in our work are consistent greatly with previous DFT calculation results ${ }^{57}$ of $0.75 \mathrm{eV}, 2.688 \AA$ and $138 \mathrm{~cm}^{-1}$. Thus, we can confirm that our calculations are precise and valid enough to investigate the properties of Cd-doped gold systems.

\section{Results and Discussion}

\subsection{Geometrical structure}

The lowest-energy structures of $\mathrm{Au}_{n+1}$ and the typical and low-lying structures of $\mathrm{Au}_{n} \mathrm{Cd}(n=1-12)$ are shown with the symmetry and relative energy of these geometries in figure 1. Meanwhile, isomers are arranged according to the order of energies from low to high.

With respect to $\mathrm{Au}_{2} \mathrm{Cd}$ clusters, the lowest-energy state $2 \mathrm{a}$ with $\mathrm{D}_{\infty \mathrm{h}}$ symmetry is a linear structure generated by a Cd atom doubly bonding with two gold atoms. The $\mathrm{C}_{\infty \mathrm{v}}$ isomer $2 \mathrm{~b}$ is also a linear structure such that $\mathrm{a}$ $\mathrm{Cd}$ atom is added to one gold atom of $\mathrm{Au}_{2}$ cluster. The isomer $2 \mathrm{c}$ is a triangular $\mathrm{C}_{2 \mathrm{v}}$ structure produced by a $\mathrm{Cd}$ atom substituting an $\mathrm{Au}$ atom of $\mathrm{Au}_{3}$ cluster.

As for $\mathrm{Au}_{3} \mathrm{Cd}$ clusters, four low-lying isomers are optimized to find the energy minima. The lowest-energy state $3 \mathrm{a}$ and the metastable state $3 \mathrm{~b}$ are rhombic structures with $\mathrm{C}_{2 \mathrm{v}}$ symmetry, which are generated by a $\mathrm{Cd}$ atom replacing a gold atom at the triply and doubly coordinated sites in $\mathrm{Au}_{4}$ cluster, respectively. The isomer $3 \mathrm{c}$ is regarded as hanging a $\mathrm{Cd}$ atom on a possible equivalent site of $\mathrm{Au}_{3}$ cluster. The isomer $3 \mathrm{~d}$ is obtained by a $\mathrm{Cd}$ atom triply bonding with three gold atoms.

For $\mathrm{Au}_{4} \mathrm{Cd}$ clusters based on the trapezoid structure of the pure $\mathrm{Au}_{5}$ cluster, the lowest-energy $4 \mathrm{a}$, isomers $4 \mathrm{~b}$ and $4 \mathrm{c}$ are obtained by substituting a $\mathrm{Cd}$ atom for one gold atom, respectively, at the triply, doubly and 


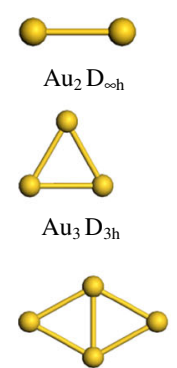

$\mathrm{Au}_{4} \mathrm{C}_{2 \mathrm{v}}$

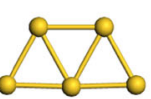

$\mathrm{Au}_{5} \mathrm{C}_{2 \mathrm{v}}$

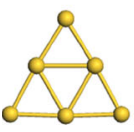

$\mathrm{Au}_{6} \mathrm{D}_{3 \mathrm{~h}}$

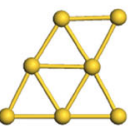

$\mathrm{Au}_{7} \mathrm{C}_{\mathrm{s}}$

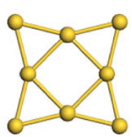

$\mathrm{Au}_{8} \mathrm{D}_{4 \mathrm{~h}}$

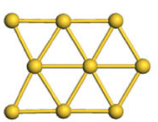

$\mathrm{Au}_{9} \mathrm{C}_{2 \mathrm{~V}}$

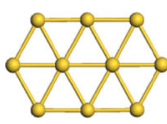

$\mathrm{Au}_{10} \mathrm{D}_{2 \mathrm{~h}}$

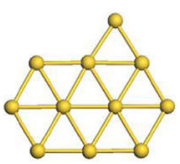

$\mathrm{Au}_{11} \mathrm{C}_{\mathrm{s}}$
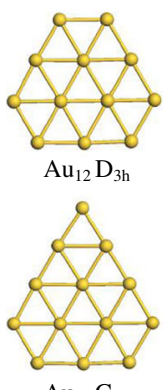

$\mathrm{Au}_{13} \mathrm{C}_{2 \mathrm{~V}}$
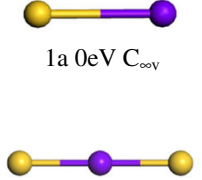

$2 \mathrm{a} 0 \mathrm{eV} \mathrm{D}_{\infty \mathrm{h}}$

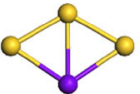

$3 \mathrm{a} 0 \mathrm{eVC}_{2 \mathrm{v}}$

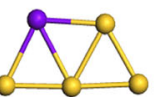

$4 \mathrm{a} 0 \mathrm{eVC}_{\mathrm{S}}$

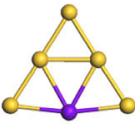

$5 \mathrm{a} 0 \mathrm{eV} \mathrm{C}_{2 \mathrm{v}}$

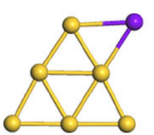

$6 \mathrm{a} 0 \mathrm{eV} \mathrm{C}_{\mathrm{S}}$

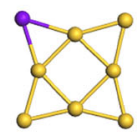

$7 \mathrm{a} 0 \mathrm{eV} \mathrm{C}_{2 \mathrm{v}}$

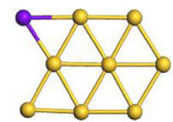

$8 \mathrm{a} 0 \mathrm{eV} \mathrm{C}_{\mathrm{S}}$

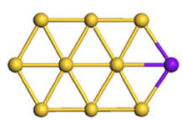

$9 \mathrm{a} 0 \mathrm{eV} \mathrm{C}_{2 \mathrm{v}}$

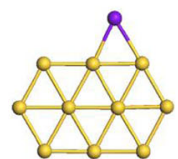

$10 \mathrm{a} 0 \mathrm{eV} \mathrm{C} \mathrm{C}_{\mathrm{S}}$
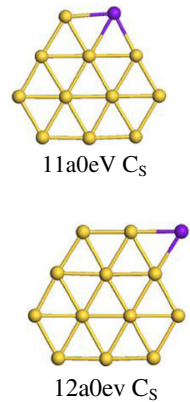

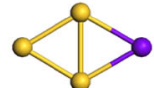

3b0.094 eVC $2 \mathrm{v}$

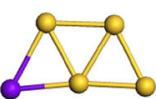

$4 \mathrm{~b} 0.316 \mathrm{eVC}_{\mathrm{S}}$

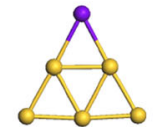

$5 \mathrm{~b} 0.059 \mathrm{eV} \mathrm{C}_{2 \mathrm{v}}$

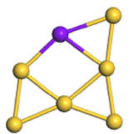

$6 \mathrm{~b} 0.073 \mathrm{eV} \mathrm{C}_{\mathrm{S}}$

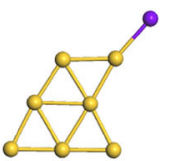

$7 \mathrm{~b} 0.283 \mathrm{eV} \mathrm{C}_{\mathrm{S}}$

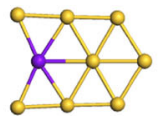

$8 \mathrm{~b} 0.179 \mathrm{eV} \mathrm{C}_{2 \mathrm{v}}$

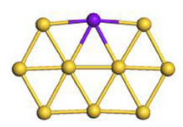

9b0.069 eV C

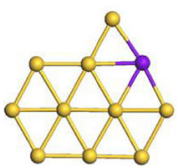

$10 \mathrm{~b} 0.113 \mathrm{eV} \mathrm{C}_{1}$
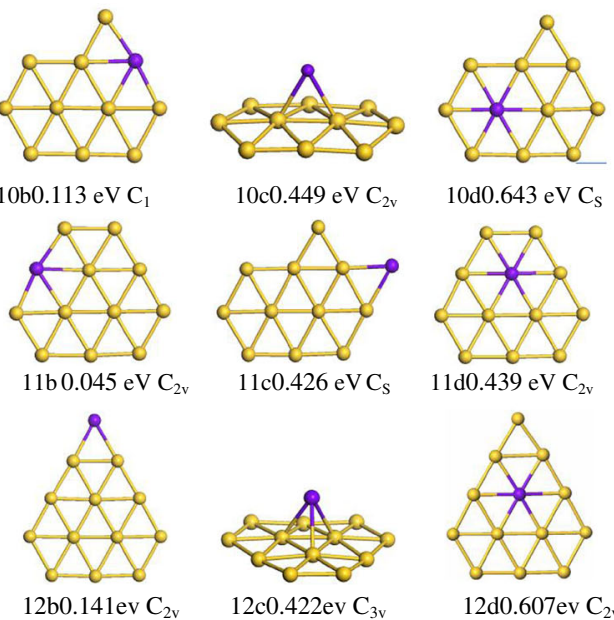

$10 \mathrm{~d} 0.643 \mathrm{eV} \mathrm{C}_{\mathrm{S}}$
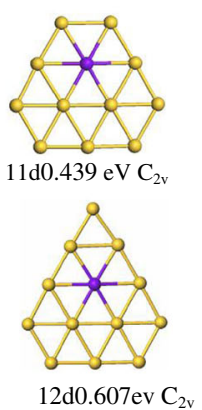

Figure 1. Optimized structures for $\mathrm{Au}_{n} \mathrm{Cd}(n=1-12)$ clusters, and the ground-state structures of pure gold clusters are shown with symmetry, and relative energy The golden and purple balls represent $\mathrm{Au}$ and $\mathrm{Cd}$ atoms, respectively. 
quadruply coordinated sites in $\mathrm{Au}_{5}$ cluster. The isomer $4 \mathrm{~d}$ is a $3 \mathrm{D}$ structure generated by placing a $\mathrm{Cd}$ atom above the plane of $\mathrm{Au}_{4}$ cluster. Compared to their initial structures, the geometrical shapes of $4 a, 4 b$ and $4 c$ are changed slightly, while the isomer $4 \mathrm{~d}$ is changed relatively obviously.

In the case of $\mathrm{Au}_{5} \mathrm{Cd}$ clusters, the lowest-energy isomer 5a is a planar $\mathrm{C}_{2 \mathrm{v}}$ structure, which is a triangle that still resembles the $\mathrm{Au}_{6}$ cluster. In the lower isomer $5 \mathrm{~b}$, the $\mathrm{Cd}$ atom is located at the doubly coordinated site in $\mathrm{Au}_{5} \mathrm{Cd}$, regarded as the metastable state. Structures of these two isomers are only minimally changed after optimization. The isomer $5 \mathrm{c}$ is obtained by hanging a $\mathrm{Cd}$ atom onto the possible non-equivalent site of $\mathrm{Au}_{5}$ cluster. The isomer $5 \mathrm{~d}$ which is produced by a $\mathrm{Cd}$ atom doubly bonding with $\mathrm{Au}_{5}$ cluster, is $0.281 \mathrm{eV}$ less stable than 5a.

For the $\mathrm{Au}_{6} \mathrm{Cd}$ cluster, the lowest-energy isomer $6 \mathrm{a}$ has a planar Cs structure, which is similar to a capped triangular structure of $\mathrm{Au}_{7}$. Initial structures of $6 \mathrm{~b}$ and $6 \mathrm{~d}$ are obtained by replacing a gold atom with a $\mathrm{Cd}$ atom at triply and quadruply coordinated sites, respectively. Additionally, the dopant $\mathrm{Cd}$ factures an $\mathrm{Au}-\mathrm{Au}$ bond inside their initial structures after optimizing. The isomer $6 \mathrm{c}$ is a $3 \mathrm{D}$ structure generated by placing a $\mathrm{Cd}$ atom on the plane of $\mathrm{Au}_{6}$.

About the $\mathrm{Au}_{7} \mathrm{Cd}$ cluster, the lowest-energy $\mathrm{C}_{2 \mathrm{v}}$ isomer $7 \mathrm{a}$ is a tera-edge-capped rhombus geometry with a $\mathrm{Cd}$ atom at the doubly coordinated site. The $\mathrm{C}_{\mathrm{S}}$ isomer $7 \mathrm{~b}$ with one $\mathrm{Au}-\mathrm{Cd}$ bond is $0.283 \mathrm{eV}$ less stable than isomer $7 \mathrm{a}$. The isomer $7 \mathrm{c}$ is produced by a $\mathrm{Cd}$ atom substituting an $\mathrm{Au}$ atom at the quadruply coordinated site in $\mathrm{Au}_{8}$ cluster. The highest-energy structure $7 \mathrm{~d}$ is a $3 \mathrm{D}$ structure, which is produced by placing a $\mathrm{Cd}$ atom above the planar structure of $\mathrm{Au}_{6}$ cluster.

With respect to the $\mathrm{Au}_{8} \mathrm{Cd}$ clusters, several typical low-lying isomers are optimized to find the energy minima. A conformation $8 \mathrm{a}$ with $\mathrm{C}_{\mathrm{S}}$ symmetry is at the lowest-energy structure. Isomers $8 \mathrm{~b}$ and $8 \mathrm{c}$ are obtained by a $\mathrm{Cd}$ atom replacing one gold atom of $\mathrm{Au}_{9}$ cluster, respectively, at the quintuply and sextuply coordinated sites. The 3D isomer $8 \mathrm{~d}$ is generated by capping a $\mathrm{Cd}$ atom above the plane of $\mathrm{Au}_{8}$ cluster. And the initial structure of $8 \mathrm{~d}$ is bent and up-swelled after optimization.

With regard to the $\mathrm{Au}_{9} \mathrm{Cdcluster}$, the lowest-energy structure $9 \mathrm{a}$, metastable configurations $9 \mathrm{~b}$ and $9 \mathrm{~d}$ can be obtained by substituting $\mathrm{Cd}$ for one gold atom at the triply, quadruply or sextuply coordinated site in $\mathrm{Au}_{10}$ cluster, respectively. The isomer $9 \mathrm{c}$ is a $3 \mathrm{D}$ structure generated by capping a $\mathrm{Cd}$ atom above the plane of $\mathrm{Au}_{9}$ cluster. Furthermore, the 3D initial structure of $9 \mathrm{c}$ is bent upwards after optimization, which is different from the 2D initial structures of $9 \mathrm{a}, 9 \mathrm{~b}$ and $9 \mathrm{~d}$.
With regard to the $\mathrm{Au}_{10} \mathrm{Cd}$ cluster, the lowest-energy state $10 \mathrm{a}$ has a planar $\mathrm{C}_{\mathrm{S}}$ geometry obtained by the impurity $\mathrm{Cd}$ atom replacing a gold atom at the doubly coordinated site in the $\mathrm{Au}_{11}$ cluster. Isomer $10 \mathrm{~b}$ is produced by a $\mathrm{Cd}$ atom substituting a gold atom with quadruple coordination number in the $\mathrm{Au}_{11}$ cluster. Isomer $10 \mathrm{c}$ is a $3 \mathrm{D}$ structure obtained by capping a $\mathrm{Cd}$ atom above the planar structure of $\mathrm{Au}_{10}$ cluster, and the impurity $\mathrm{Cd}$ atom draws $\mathrm{Au}_{10}$ upwards. The energy isomer $10 \mathrm{~d}$ is the planar structure obtained by a $\mathrm{Cd}$ atom replacing a gold atom at sextuply coordinated site in $\mathrm{Au}_{11}$ cluster.

With respect to the $\mathrm{Au}_{11} \mathrm{Cd}$ cluster, the lowest-energy structure $11 \mathrm{a}$ is produced by a $\mathrm{Cd}$ atom replacing an $\mathrm{Au}$ atom with the triply co-ordinated number in $\mathrm{Au}_{11} \mathrm{Cd}$. The isomer $11 \mathrm{~b}$ is $0.045 \mathrm{eV}$ less stable than $11 \mathrm{a}$, which is obtained by a $\mathrm{Cd}$ atom substituting an $\mathrm{Au}$ atom at the quadruply coordinated site in $\mathrm{Au}_{12}$. The isomer $11 \mathrm{c}$ is regarded as placing a $\mathrm{Cd}$ atom at a side of the $\mathrm{Au}_{11}$ cluster with two $\mathrm{Au}-\mathrm{Cd}$ bonds. The isomer $11 \mathrm{~d}$ is obtained by a $\mathrm{Cd}$ atom replacing an $\mathrm{Au}$ atom at the sextuply coordinated site in the $\mathrm{Au}_{12}$ cluster. Besides, the shapes of $11 \mathrm{a}, 11 \mathrm{~b}$ and $11 \mathrm{~d}$ still resemble a pentacapped hexagon structure of a pure $\mathrm{Au}_{12}$ cluster.

For the $\mathrm{Au}_{12} \mathrm{Cd}$ clusters the $\mathrm{C}_{\mathrm{S}}$ isomer $12 \mathrm{a}$ is the lowest-energy structure produced by a $\mathrm{Cd}$ atom doubly bonding with $\mathrm{Au}_{12}$. The metastable state $12 \mathrm{~b}$ is generated by a $\mathrm{Cd}$ atom substituting an $\mathrm{Au}$ atom at the doubly site in $\mathrm{Au}_{13}$. The isomer $12 \mathrm{c}$ is a $3 \mathrm{D} \mathrm{C}_{3 \mathrm{v}}$ structure obtained by capping a $\mathrm{Cd}$ atom above the planar structure of $\mathrm{Au}_{12}$ cluster, and this geometrical structure of $12 \mathrm{~d}$ is bent to some extent. The isomer $12 \mathrm{~d}$ with six $\mathrm{Au}-$ $\mathrm{Cd}$ bonds is generated by a $\mathrm{Cd}$ atom replacing a gold atom at the highest coordinated site in the $\mathrm{Au}_{13}$ cluster.

According to the analysis on geometries of $\mathrm{Au}_{n} \mathrm{Cd}$, for lowest-energy geometries of $\mathrm{Au}_{n} \mathrm{Cd}$, the dopant $\mathrm{Cd}$ atom has a higher coordination number at $n=2-6$ but a lower coordination number at $n=7-12$. In the meantime, after optimizing, 3D structures are distorted obviously, while 2D structures are distorted slightly and still resemble initial structures. Moreover, all the lowest-energy structures of $\mathrm{Au}_{n} \mathrm{Cd}$ clusters are 2D structures, signifying that scalar relativistic effects significantly influence the clusters composed of heavy elements. . $^{33,38,42,45,46}$ Usually, the scalar relativistic effect is obvious and cannot be neglected in gold clusters or gold-based mixed metal clusters. The strong scalar relativistic effect caused by the high-speed motion of outer shell electrons and the spin-orbit coupling leads to the shrinking size of the $s$ orbitals and therefore enhances the $s-d$ hybridization and causes the frontier orbitals to disperse. Furthermore, the strengthened $s-d$ hybridization lowers the corresponding energy 
level and enhances the shielding effect of inner electrons. This favours planar bonding and thus drives the planarity of clusters. In addition, the lowest-energy structures in the previous literatures ${ }^{31,45,58}$ are found to be planar geometries likewise, which is similar to the conclusion of our works.

\subsection{Stability trends}

The average binding energy of clusters is a measure of cluster stability, which is defined as

$$
\begin{aligned}
& E_{b}\left(\mathrm{Au}_{n} \mathrm{Cd}\right)=[ n E(\mathrm{Au})+E(\mathrm{Cd}) \\
&\left.-E\left(\mathrm{Au}_{n} \mathrm{Cd}\right)\right] /(n+1) \\
& E_{b}\left(\mathrm{Au}_{n+1}\right)=\left[(n+1) E(\mathrm{Au})-E\left(\mathrm{Au}_{n+1}\right)\right] /(n+1),
\end{aligned}
$$

where $E\left(\mathrm{Au}_{n} \mathrm{Cd}\right), E\left(\mathrm{Au}_{n+1}\right), E(\mathrm{Au})$ and $E(\mathrm{Cd})$ represent the total energies of the lowest-energy structures for $\mathrm{Au}_{n} \mathrm{Cd}, \mathrm{Au}_{n+1}, \mathrm{Au}$ and $\mathrm{Cd}$, respectively.

As seen from figure 2, we can see that the tendency for a similar change of the average binding energy on both $\mathrm{Au}_{n} \mathrm{Cd}$ and $\mathrm{Au}_{n+1}$. The average binding energy of pure gold cluster and gold cluster doped with $\mathrm{Cd}$ atom increases gradually with increase in cluster size, meaning the cluster stability is enhanced when the cluster size grows. Besides, the average binding energy of $\mathrm{Au}_{n} \mathrm{Cd}$ shows a monotonically increasing pattern, namely the stability of $\mathrm{Au}_{n} \mathrm{Cd}$ gradually increases and reaches maximum $\mathrm{Au}_{12} \mathrm{Cd}$. This reflects the fact that the larger the size of the cluster, the more stable is the cluster.

To further explore the stabilities of the $\mathrm{Au}_{n} \mathrm{Cd}$ clusters and the size-dependent properties, the fragmentation energy is calculated and plotted in figure 3. The

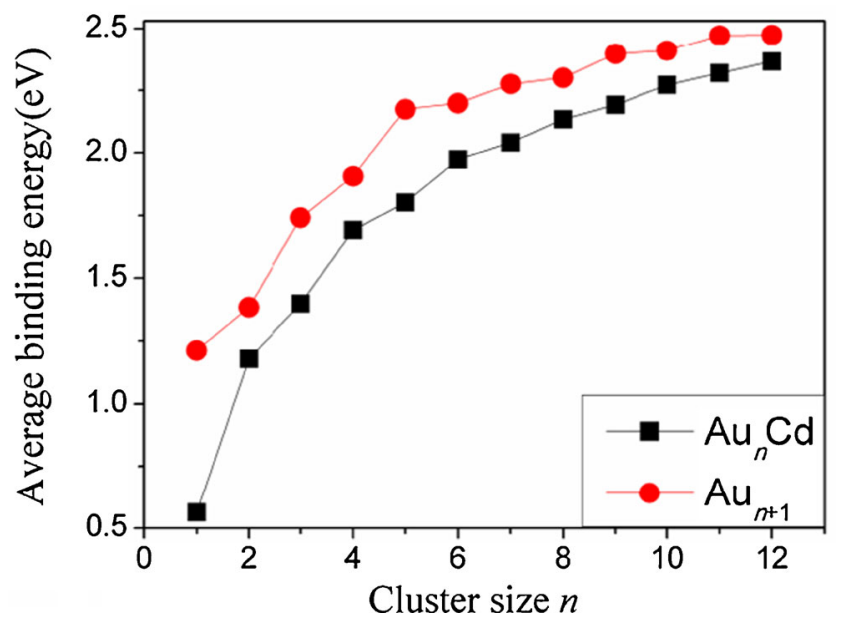

Figure 2. Size dependence of the atomic average binding energies.

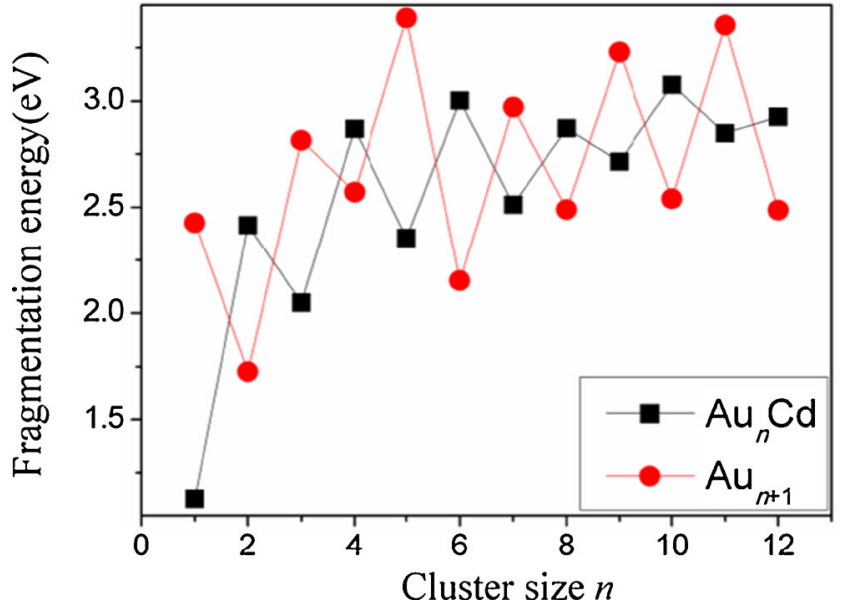

Figure 3. Size dependence of the fragmentation energies.

fragmentation energy can be defined by the following formulas:

$$
\begin{aligned}
& E_{f}\left(\mathrm{Au}_{n+1}\right)=\left[E\left(\mathrm{Au}_{n}\right)+E(\mathrm{Au})-E\left(\mathrm{Au}_{n+1}\right)\right] \\
& E_{f}\left(\mathrm{Au}_{n} \mathrm{Cd}\right)=\left[E\left(\mathrm{Au}_{n-1} \mathrm{Cd}\right)+E(\mathrm{Au})-E\left(\mathrm{Au}_{n} \mathrm{Cd}\right)\right] .
\end{aligned}
$$

From figure 3 , we can find that the fragmentation energies of $\mathrm{Au}_{n} \mathrm{Cd}$ and $\mathrm{Au}_{n+1}$ clusters both show the obvious even-odd oscillation in the reverse order with increase in cluster size. The values of even-numbered $\mathrm{Au}_{n} \mathrm{Cd}$ are larger than those of odd-numbered $\mathrm{Au}_{n} \mathrm{Cd}$ and corresponding even-numbered $\mathrm{Au}_{n+1}$, signifying that an impurity $\mathrm{Cd}$ atom can change the stable pattern of pure gold clusters, and namely even-numbered $\mathrm{Au}_{n} \mathrm{Cd}$ are more stable than odd-numbered $\mathrm{Au}_{n} \mathrm{Cd}$ and even-numbered $\mathrm{Au}_{n+1}$. Second-order difference of cluster energy, as a function of cluster size, is a greatly sensitive parameter to reveal the relative stability of cluster. We define the relevant formulas as follows:

$$
\begin{aligned}
& D_{2} E(n)=E\left(\mathrm{Au}_{n+1}\right)+E\left(\mathrm{Au}_{n-1}\right)-2 E\left(\mathrm{Au}_{n}\right) \\
& D_{2} E(n)=E\left(\mathrm{Au}_{n+1} \mathrm{Cd}\right)+E\left(\mathrm{Au}_{n-1} \mathrm{Cd}\right)-2 E\left(\mathrm{Au}_{n} \mathrm{Cd}\right),
\end{aligned}
$$

As can be seen in figure 4, we can also observe that $\mathrm{Au}_{n} \mathrm{Cd}$ has opposite even-odd oscillation, with $\mathrm{Au}_{n+1}$ on second-order difference of cluster energy with the increase in cluster size. This means that the presence of $\mathrm{Cd}$ changes the relative stability pattern of $\mathrm{Au}_{n+1}$, namely the even-numbered $\mathrm{Au}_{n} \mathrm{Cd}$ are relatively more stable than the corresponding $\mathrm{Au}_{n+1}$ and neighbouring odd-numbered $\mathrm{Au}_{n} \mathrm{Cd}$.

According to the above discussion, we show that $\mathrm{Au}_{2,4,6,8,10,12} \mathrm{Cd}$ have pronouncedly relative stability compared to the neighbouring odd-numbered ones and corresponding even-numbered $\mathrm{Au}_{n+1}$. This case is better explained by the electron paired effect. In the 


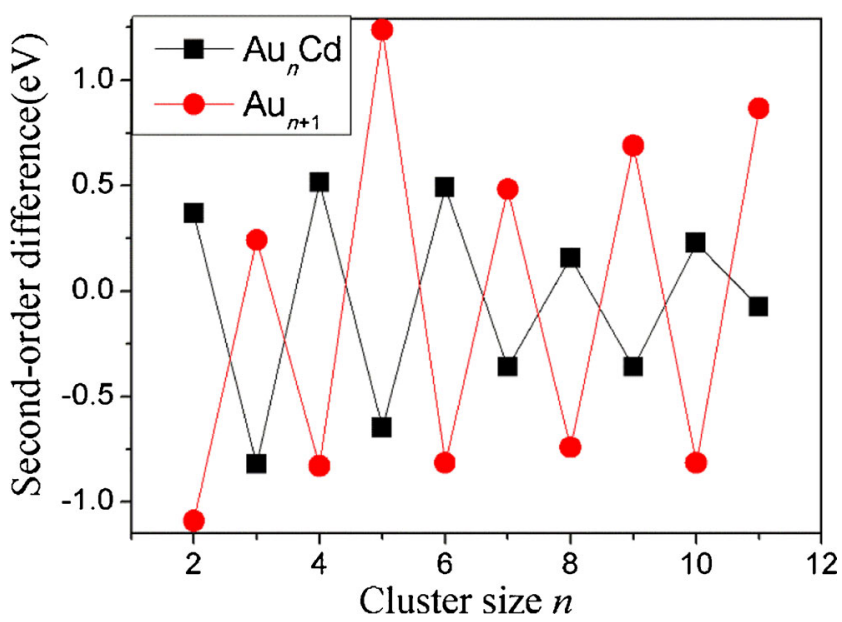

Figure 4. Size dependence of the second-order difference of energies.

meantime, by comparison between the electronic structures of $\mathrm{Au}_{n} \mathrm{Cd}$ and $\mathrm{Au}_{n+1}$ we can find that the evennumbered $\mathrm{Au}_{n+1}$ systems have odd number of valence electrons and the odd-numbered $\mathrm{Au}_{n+1}$ systems have even number of valence electrons; however the evennumbered $\mathrm{Au}_{n} \mathrm{Cd}$ systems possess even number of valence electrons and the odd-numbered $\mathrm{Au}_{n} \mathrm{Cd}$ systems possess odd number of valence electrons. This suggests that the occurrence of dopant $\mathrm{Cd}$ atom changes the electronic structures of host gold clusters. In the following section, we further analyze the influence of impurity $\mathrm{Cd}$ atom on the electronic properties of host gold clusters.

\subsection{Electronic properties}

The energy gap between the highest occupied molecular orbital (HOMO) and the lowest unoccupied molecular orbital (LUMO) is a useful quantity on electronic stability of clusters. The larger the HOMO-LUMO gap, the higher the energy required to excite the electrons from valence band to conduction band, which means stability of electronic structure is higher.

As shown in figure 5 we can observe that $\mathrm{Au}_{n} \mathrm{Cd}$ and $\mathrm{Au}_{n+1}$ have obvious even-odd oscillations for the HOMO-LUMO gap. The $\mathrm{Au}_{n} \mathrm{Cd}$ clusters with even number of valence electrons have comparatively larger energy gap than the neighbouring $\mathrm{Au}_{n} \mathrm{Cd}$ with odd number of valence electrons and corresponding $\mathrm{Au}_{n+1}$ with even-number of valence electrons, meaning that the doped clusters with even number of valence electrons have higher electronic stability than neighbouring $\mathrm{Au}_{n} \mathrm{Cd}$ with odd-number of valence electrons and corresponding $\mathrm{Au}_{n+1}$ with even-number of valence electrons. This indicates that the presence of dopant

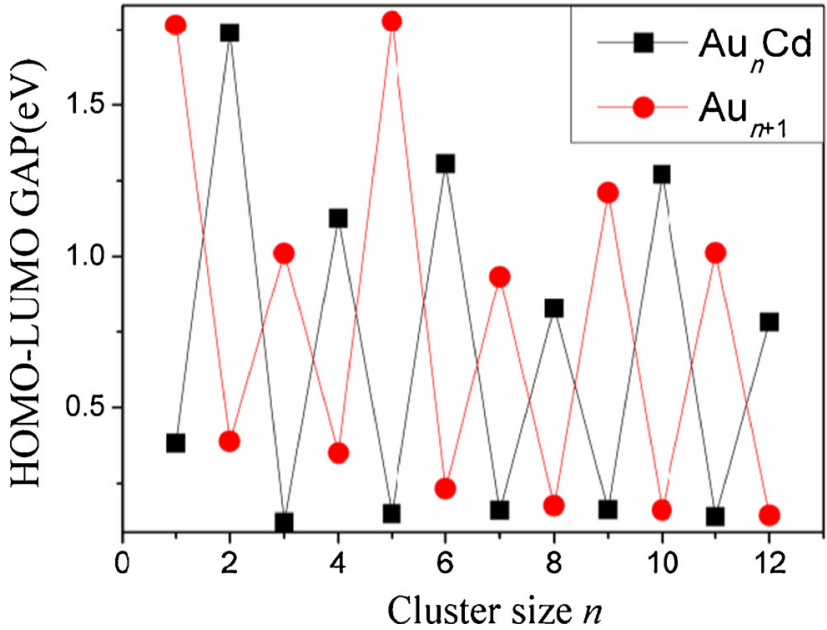

Figure 5. Size dependence of the HOMO-LUMO energy gaps.

$\mathrm{Cd}$ atom obviously changes the electronic structure of $\mathrm{Au}_{n+1}$. Moreover, this situation reflects that the system with even-number of valence electrons has higher stable electronic structure than the adjacent system with odd number of valence electrons.

To further reveal the influence of the electron properties caused by the impurity atom $\mathrm{Cd}$, we implement the thorough Mulliken population analysis summarized in table 1 for pure $\mathrm{Au}_{n+1}$ clusters and $\mathrm{Au}_{n} \mathrm{Cd}$ clusters. The configurations of single $\mathrm{Au}$ and $\mathrm{Cd}$ atoms are $5 d^{10} 6 s^{1}, 4 d^{10} 5 s^{2}$ of valence electrons and empty $5 p, 6 p$ orbitals respectively. In terms of the Mulliken population analysis in table 1 , the $\mathrm{Cd}$ atom in $\mathrm{Au}_{n} \mathrm{Cd}$ cluster obviously has positive charge, signifying that the charges transfer from $\mathrm{Cd}$ atom to $\mathrm{Au}$ atoms, and that the $\mathrm{Cd}$ atom acts as an electronic donor, while most $\mathrm{Au}$ atoms act as electronic hosts. With regard to the impurity $\mathrm{Cd}$ atom, we figure out that the $4 s$ states lose 0.412 0.870 electrons, while the $5 p$ states receive $0.120-0.445$ electrons for $\mathrm{Au}_{n} \mathrm{Cd}$ clusters. Particularly, the contribution of the $4 d$ states is $0.001-0.006$ electrons as nearly zero, and thus it can be neglected. These indicate that there is strong $s-p$ hybridization in the $\mathrm{Cd}$ atom or between the $\mathrm{Cd}$ atom and $\mathrm{Au}$ atoms in $\mathrm{Au}_{n} \mathrm{Cd}$, which differs from the $s p d$ hybridization in the corresponding $\mathrm{Au}$ of $\mathrm{Au}_{n+1}$. Besides, 9.997-10.005 electrons occupy the $4 d$ orbital of $\mathrm{Cd}$ atoms in $\mathrm{Au}_{n} \mathrm{Cd}$, signifying that the $4 d$ orbital of dopant $\mathrm{Cd}$ atom as well as the $5 d$ orbital of $\mathrm{Au}$ atoms in $\mathrm{Au}_{n} \mathrm{Cd}$ clusters are dominant core orbitals.

The HOMO and the LUMO are plotted in figure 6. We can clearly observe that for $\mathrm{Au}_{n} \mathrm{Cd}$ with even number of valence electrons, HOMO as well as LUMO is a doubly degenerate state. The even-numbered $\mathrm{Au}_{n} \mathrm{Cd}$ has an even number of $s$ valence electrons and the paired $s$ valence electrons with reverse spins doubly 
Table 1. Calculated charges populations of $4 d, 5 s, 5 p$ orbitals of $\mathrm{Cd}$ in $\mathrm{Au}_{n} \mathrm{Cd}$ clusters and $5 d, 6 s, 6 p$ orbitals of corresponding $\mathrm{Au}$ in $\mathrm{Au}_{n+1}$ clusters.

\begin{tabular}{|c|c|c|c|c|c|c|c|c|}
\hline \multirow[b]{2}{*}{$n$} & \multicolumn{4}{|c|}{$\mathrm{Au}_{n} \mathrm{Cd}$} & \multicolumn{4}{|c|}{$\mathrm{Au}_{n+1}$} \\
\hline & $4 d$ & $5 s$ & $5 p$ & $\mathrm{Cd}$ & $5 d$ & $6 s$ & $6 p$ & $\mathrm{Au}$ \\
\hline 1 & 9.997 & 1.543 & 0.205 & 0.255 & 9.870 & 0.863 & 0.069 & 0.198 \\
\hline 2 & 9.997 & 1.588 & 0.120 & 0.295 & 9.782 & 0.871 & 0.193 & 0.154 \\
\hline 3 & 9.999 & 1.199 & 0.411 & 0.391 & 9.760 & 0.802 & 0.337 & 0.101 \\
\hline 4 & 9.997 & 1.477 & 0.228 & 0.298 & 9.622 & 0.879 & 0.440 & 0.059 \\
\hline 5 & 10.005 & 1.130 & 0.445 & 0.420 & 9.664 & 0.889 & 0.408 & 0.039 \\
\hline 6 & 9.998 & 1.577 & 0.208 & 0.217 & 9.556 & 0.824 & 0.542 & 0.078 \\
\hline 7 & 9.994 & 1.430 & 0.252 & 0.324 & 9.620 & 0.914 & 0.451 & 0.015 \\
\hline 8 & 9.996 & 1.457 & 0.252 & 0.295 & 9.526 & 0.786 & 0.602 & 0.086 \\
\hline 9 & 10.001 & 1.333 & 0.344 & 0.322 & 9.516 & 0.775 & 0.613 & 0.096 \\
\hline 10 & 9.995 & 1.475 & 0.233 & 0.297 & 9.473 & 0.817 & 0.639 & 0.071 \\
\hline 11 & 9.998 & 1.301 & 0.358 & 0.343 & 9.471 & 0.827 & 0.642 & 0.060 \\
\hline 12 & 9.996 & 1.489 & 0.226 & 0.289 & 9.473 & 0.834 & 0.630 & 0.063 \\
\hline
\end{tabular}

occupy the HOMO, while the odd-numbered cluster has an unpaired $s$ valence electron and the HOMO is singly occupied. The electron in a doubly occupied HOMO feels a stronger effective core potential because the electron screening is weaker for electrons in the same orbital than for inner-shell electrons. Hence, the binding

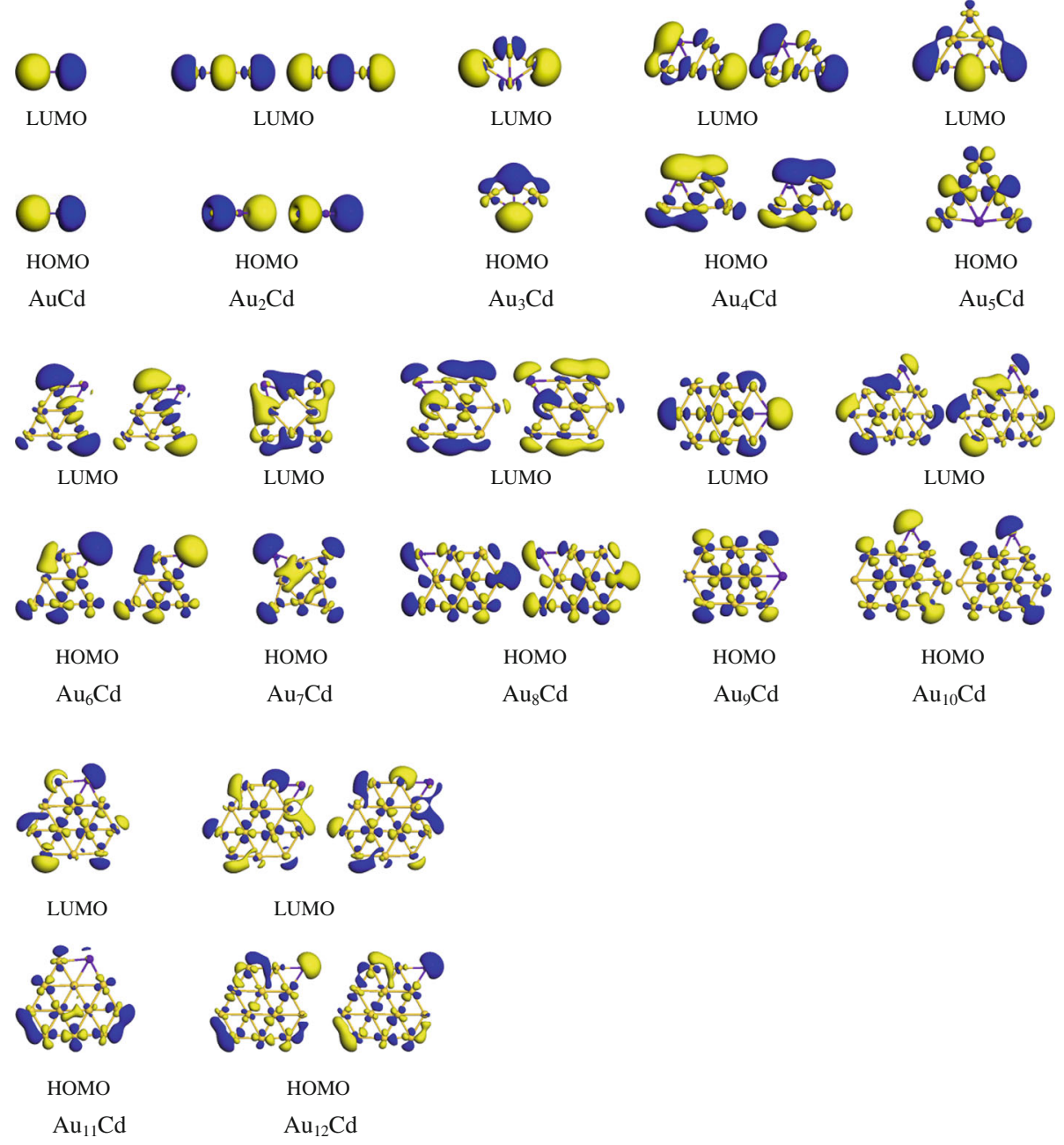

Figure 6. Molecular orbitals HOMO and LUMO for $\mathrm{Au}_{n} \mathrm{Cd}$. 
energy of a valence electron in even-numbered $\mathrm{Au}_{n} \mathrm{Cd}$ is larger than that of odd-numbered one. This further verifies that the stability of even-numbered $\mathrm{Au}_{n} \mathrm{Cd}$ is higher than that of odd-numbered ones. Besides, due to the presence of dopant $\mathrm{Cd}$ atom, the distribution of electron cloud of $\mathrm{Au}_{n} \mathrm{Cd}$ is no longer symmetric, uniform and well-mixed. Specifically, the delocalization of HOMO and LUMO is impaired obviously. In particular, for HOMOs of $\mathrm{Au}_{2,5,9,11} \mathrm{Cd}$ systems, relatively little electron cloud appears around the impurity $\mathrm{Cd}$ atom. Additionally, it is noted that the overlap of electron cloud between the frontier orbitals of $\mathrm{Cd}$ and $\mathrm{Au}$ in $\mathrm{Au}_{n} \mathrm{Cd}$ shows the pronounced $s-p$ hybridization. Furthermore, the $s-p$ overlap and the relativistic effects in $\mathrm{Au}_{n} \mathrm{Cd}$ enhance the planarity of low-lying structures.

With the aim of having a clear view of the electron transferring between the dopant $\mathrm{Cd}$ and $\mathrm{Au}$ atoms, the electron deformation densities of several representative $\mathrm{Au}_{n} \mathrm{Cd}$ and corresponding $\mathrm{Au}_{n+1}$ for the lowest-energy structures as examples are plotted in figure 7 and the blue area represents electron accumulations. The electron deformation density in $\mathrm{Au}_{n} \mathrm{Cd}$ clusters shows that just a few electrons distribute around the $\mathrm{Cd}$ atom and in the interval of $\mathrm{Au}-\mathrm{Cd}$ bonds compared with electron distributions around adjacent $\mathrm{Au}$ atoms and in the interval of $\mathrm{Au}-\mathrm{Au}$ bonds. This means more obviously ionic-like characteristics in the $\mathrm{Au}-\mathrm{Cd}$ bond than that in the $\mathrm{Au}-\mathrm{Au}$ bond. By contrast with pure $\mathrm{Au}_{n+1}$ clusters, the electron accumulation between the $\mathrm{Cd}$ and $\mathrm{Au}$ atoms markedly decreases when the impurity $\mathrm{Cd}$ atom replaces an $\mathrm{Au}$ atom. This case indicates that a weaker $\mathrm{Au}-\mathrm{Cd}$ interaction exists in $\mathrm{Au}_{n} \mathrm{Cd}$ than the corresponding $\mathrm{Au}-\mathrm{Au}$ interaction in $\mathrm{Au}_{n+1}$.
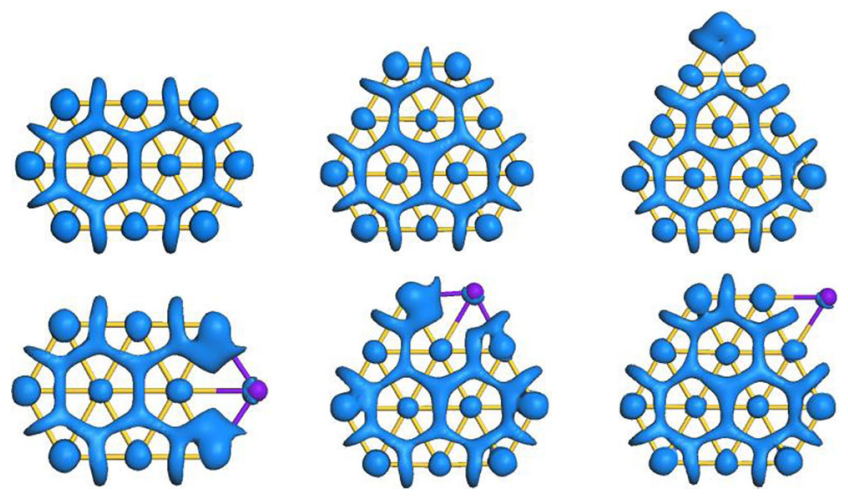

Figure 7. Comparison on electron deformation density of $\mathrm{Au}_{n} \mathrm{Cd}$ clusters and corresponding $\mathrm{Au}_{n+1}$ clusters for the lowest-energy structures with surface isovalue 0.023 e/Åì for molecular orbital plotting.

\subsection{Chemical reactivity}

Chemical hardness is regarded as a crucial parameter to assess reactivity of a system, where $(\boldsymbol{\eta})$ may be approximated as

$$
\eta=(V I P-V E A) / 2,
$$

where VIP and VEA are vertical ionization potential and the vertical electron affinity, respectively. As can be seen in figure 8, the chemical hardness of $\mathrm{Au}_{n} \mathrm{Cd}$ with even number of valence electrons is higher than that of the neighbouring $\mathrm{Au}_{n} \mathrm{Cd}$ with odd number of valence electrons and corresponding $\mathrm{Au}_{n+1}$. Therefore, according to the principle of maximum hardness $(\mathrm{PMH}){ }^{59}$ we can infer that $\mathrm{Au}_{n} \mathrm{Cd}$ with even number of valence electrons have higher chemical stability than neighbouring $\mathrm{Au}_{n} \mathrm{Cd}$ with odd number of valence electrons and corresponding $\mathrm{Au}_{n+1}$. This demonstrates the impurity $\mathrm{Cd}$ atom can change the chemical stability model of pure gold cluster. In other words, the chemical reactivity of $\mathrm{Au}_{n} \mathrm{Cd}$ with odd number of valence electrons is stronger than that of corresponding $\mathrm{Au}_{n+1}$ and neighbouring $\mathrm{Au}_{n} \mathrm{Cd}$ with even number of valence electrons. This phenomenon may be explained as an unpaired valence electron of $\mathrm{Au}_{n} \mathrm{Cd}$ with odd number of valence electrons leading to these clusters being strongly reactive, so the chemical stability of odd-numbered $\mathrm{Au}_{n} \mathrm{Cd}$ is greatly lower than that of even-numbered ones.

It is found that the odd-even variation of chemical hardness is greatly consistent with the odd-even variations of the HOMO-LUMO energy gap, fragmentation and second order difference energies. These phenomena reveal that since there is the valence paired effect in $\mathrm{Au}_{n} \mathrm{Cd}$ system, $\mathrm{Au}_{2,4,6,8,10,12} \mathrm{Cd}$ system with even number of valence electrons are markedly more

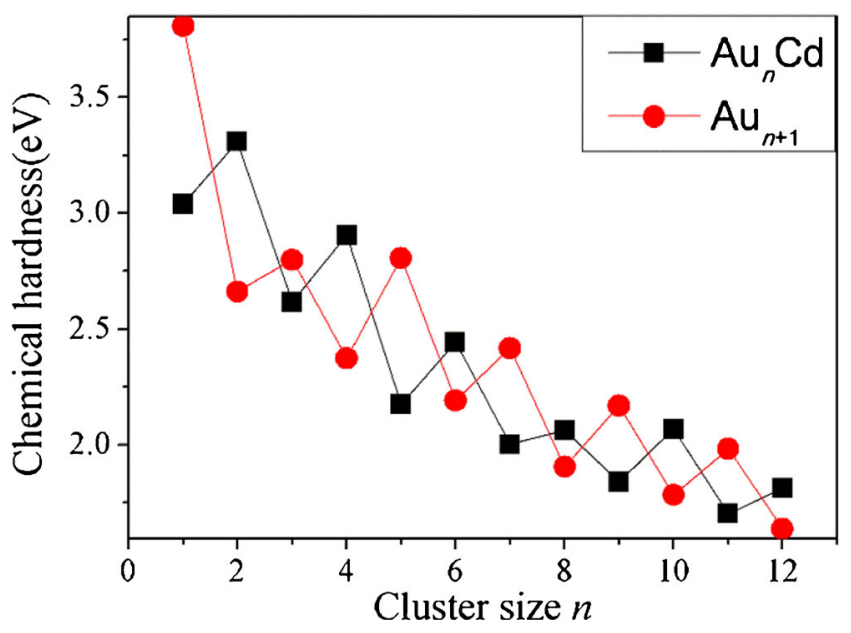

Figure 8. Size dependence of chemical hardness. 
stable than adjacent $\mathrm{Au}_{n} \mathrm{Cd}$ system with odd number of valence electrons and corresponding $\mathrm{Au}_{n+1}$ with odd number valence electrons geometrically, electronically and chemically.

\section{Conclusions}

We have systematically investigated the low-energy geometrical structures, growth-pattern behaviours, relative stabilities, chemical stabilities and electronic property of $\mathrm{Au}_{n} \mathrm{Cd}$ clusters by applying all-electron relativistic density functional theory with generalized gradient approximation.

1) In all geometrical structures, most low-lying energy structures are inclined to be 2D structures that have slight deformation and resemble the corresponding initial geometrical structures because of the strong scalar relativistic effects in $\mathrm{Au}_{n} \mathrm{Cd}$ clusters. Notably, for the lowest-energy structures the dopant $\mathrm{Cd}$ atom has higher coordination number at $n=2-6$, while it has lower coordination number at $n=7-12$ and is located at the edge of structures.

2) The fragmentation energies, second-order difference of energies and HOMO-LUMO energy gaps of $\mathrm{Au}_{n} \mathrm{Cd}$ and $\mathrm{Au}_{n+1}$ show markedly odd-even oscillations in the reverse order. Namely, the geometrical and electronic stabilities of $\mathrm{Au}_{n} \mathrm{Cd}$ with even number of valence electrons are higher than those of neighbouring $\mathrm{Au}_{n} \mathrm{Cd}$ and corresponding $\mathrm{Au}_{n+1}$ with odd number of valence electrons; besides, $\mathrm{Au}_{n} \mathrm{Cd}$ with odd number valence of electrons are chemically less stable and more reactive than corresponding $\mathrm{Au}_{n+1}$ clusters and neighbouring $\mathrm{Au}_{n} \mathrm{Cd}$ with even number of valence electrons. These imply that the presence of impurity $\mathrm{Cd}$ atom pronouncedly changes the stability trend of host gold clusters.

3) Mulliken population discovered that the $\mathrm{Cd}$ atom is the electronic donor and most $\mathrm{Au}$ atoms are the electronic hosts, and that there is the obvious charge transfer from the $\mathrm{Cd}$ atom to $\mathrm{Au}$ atoms for $\mathrm{Au}_{n} \mathrm{Cd}$. Meanwhile, for the impurity $\mathrm{Cd}$ atom, the $4 s$ orbitals lose $0.412-0.870$ electrons, $4 p$ orbitals receive $0.120-0.445$ electrons, and the contribution of the $4 d$ orbitals is $0.001-0.006$ electrons as nearly zero. Hence it is found that the impurity obviously alters the electronic structure of host gold clusters. Especially, there are the strong $s-p$ orbital interaction in the $\mathrm{Cd}$ atom or between the $\mathrm{Cd}$ atom and $\mathrm{Au}$ atoms in $\mathrm{Au}_{n} \mathrm{Cd}$, which differs from the $s p d$ orbital interaction in the corresponding $\mathrm{Au}$ of
$\mathrm{Au}_{n+1}$ Besides, the less electron accumulation in the intervals between $\mathrm{Cd}$ and $\mathrm{Au}$ atoms indicates that $\mathrm{Au}-\mathrm{Cd}$ bonds of $\mathrm{Au}_{n} \mathrm{Cd}$ clusters are weaker and have more obviously ionic-like characteristics than corresponding $\mathrm{Au}-\mathrm{Au}$ bonds of $\mathrm{Au}_{n+1}$.

\section{Acknowledgements}

This work was supported by the Fundamental Research Funds for the Central Universities (No.CDJXS0233005302101).

\section{References}

1. Li X, Kuznetsov A E, Zhang H F, Boldyrev A I and Wang L S 2001 Science 291859

2. Menon M 2001 J. Chem. Phys. 1147731

3. Iwasa T and Nakajima A 2012 J. Phys. Chem. C 116 14071

4. David J, Guerra D, Hadad C and Restrepo 2010 J. Phys. Chem. A 11410726

5. David J, Guerra D and Restrepo 2012 Chem. Phys. Lett. 53964

6. Nhat P V and Nguyen M T 2011 Phys. Chem. Chem. Phys. 1316254

7. Heinebrodt M et al. 1999 J. Chem. Phys. 1109915.

8. Wang L M, Pal R, Huang W, Zeng X C and Wang L S 2010 J. Chem. Phys. 132114306

9. Bonačić-Koutecký V et al. 2002 J. Chem. Phys. 117 3120.

10. Yuan D, Wang Y and Zeng Z 2005 J. Chem. Phys. 122 114310

11. Torres M, Fernández E and Balbás L 2005 Phys. Rev. B 71155412

12. Neukermans S, Janssens E, Tanaka H, Silverans R and Lievens P 2003 Phys. Rev. Lett. 9033401

13. Fernández E, Torres M and Balbás L 2009 Eur. Phys. J. D 52135

14. Neumaier M, Weigend F, Hampe O and Kappes M M 2008 Faraday Discuss 138393

15. Hirabayashi $\mathrm{S}$, Ichihashi M, Kawazoe $\mathrm{Y}$ and Kondow $\mathrm{T}$ 2012 J. Phys. Chem. A 1168799

16. Nhat P V, Tai T B and Nguyen M T 2012 J. Chem. Phys. 137164312

17. Van De Walle J, Tarento R and Joyes P 1999 Surf. Rev. Lett. 6307

18. Janssens E, Tanaka H, Neukermans S, Silverans R E and Lievens P 2003 New J. Phys. 546

19. Zhang M, He L M, Zhao L X, Feng X J and Luo Y H 2009 J. Phys. Chem. C 1136491

20. Zhong D C et al. 2012 Cryst. Growth Des. 121992

21. Dindulkar S D, Reddy M V and Jeong Y T 2012 Catal. Commun. 17114

22. Frischmann P D and MacLachlan M J 2007 Chem. Commun. 4480

23. Seoudi R, Elokr M, Shabaka A and Sobhi A 2008 Physica B $\mathbf{4 0 3} 152$

24. Rzigalinski B A and Strobl J S 2009 Toxicol. Appl. Pharmacol. 238280 
25. Asaka K, Hirotsu Y and Tadaki T 2001 Mater. Sci. Eng. A 312232

26. Frommen C, Wilde G and Rösner H 2004 J. Alloys Compd. 377232

27. Cotton F A, Wilkinson G, Murillo C and Bochmann M 1999 In Advanced Inorganic Chemistry (New York: John Wiley \& Sons)

28. Koyasu K, Naono Y, Akutsu M, Mitsui M and Nakajima A 2006 Chem. Phys. Lett. 42262

29. Tanaka H, Neukermans S, Janssens E, Silverans R E and Lievens P 2003 J. Chem. Phys. 1197115

30. Rykova E, Zaitsevskii A, Mosyagin N, Isaev T and Titov A 2006 J. Chem. Phys. 125241102

31. Zaleski Ejgierd P and Pyykko P 2009 J. Phys. Chem. A 11312380

32. Manna D, Jayasekharan T and Ghanty T K 2013 J. Phys. Chem. $C$

33. Lee Y S, Ermler W C and Pitzer K S 1977 J. Chem. Phys. 675861

34. Delley B 2000 J. Chem. Phys. 1137756

35. Delley B 1990 J. Chem. Phys. 92508

36. Becke A D 1988 J. Chem. Phys. 882547

37. Perdew J P and Wang Y 1992 Phys. Rev. B 4513244

38. Autschbach J, Siekierski S, Seth M, Schwerdtfeger P and Schwarz W 2002 J. Comput. Chem. 23804

39. Datta S N, Ewig C S and Van Wazer J R 1978 Chem. Phys. Lett. 5783

40. Stevens W J, Krauss M, Basch H and Jasien P G 1992 Can. J. Chem. 70612

41. Wildman S, DiLabio G and Christiansen P 1997 J. Chem. Phys. 1079975
42. Jain P K 2005 Struct. Chem. 16421

43. Wang J, Wang $\mathrm{G}$ and Zhao J 2002 Phys. Rev. B 66 035418

44. Gilb S, Weis P, Furche F, Ahlrichs R and Kappes M M 2002 J. Chem. Phys. 1164094

45. Fernández E M, Soler J M, Garzón I L and Balbás L C 2004 Phys. Rev. B 70165403

46. Wesendrup R, Hunt $T$ and Schwerdtfeger P 2000 J. Chem. Phys. 1129356

47. Deka A and Deka R C 2008 J. Mol. Struct. 87083

48. Häkkinen H and Landman U 2000 Phys. Rev. B 622287

49. Lee H M, Ge M, Sahu B, Tarakeshwar P and Kim K S 2003 J. Phys. Chem. B 1079994

50. Torres M B, Fernández E M and Balbás L C 2005 Phys. Rev. B 71155412

51. Simard B and Hackett P 1990 J. Mol. Spectrosc. 142310

52. Ho J, Ervin K M and Lineberger W 1990 J. Chem. Phys. 936987

53. Ames L and Barrow R 1967 Trans. Faraday Soc. 63 39

54. Huber K P and Herzberg G 1979 In Constants of diatomic molecules (New York: Van Nostrand Reinhold)

55. Jules J L and Lombardi J R 2003 J. Phys. Chem. A 107 1268

56. Morse M D 1986 Chem. Rev. 861049

57. Wu Z 2005 Chem. Phys. Lett. 40624

58. Wang H Q, Kuang X Y and Li H F 2009 J. Phys. Chem. A 11314022

59. Pearson R G and Pearson R 1997 In Chemical hardness: applications from molecules to solids (Weinheim: Wiley-VCH) 